\title{
Health Monitoring System with Hybrid Laser Sensor Networks and Cloud Computing for Subway Tunnels
}

\author{
Fu-guang Zhu, ${ }^{1}$ Dong-sheng Xu $\mathbb{D}^{\mathrm{D}},{ }^{2}$ Rui-shan Tan, ${ }^{1}$ Bin Peng, ${ }^{1}$ He Huang, \\ and Zhuo-wen Liu $^{2}$ \\ ${ }^{1}$ Hubei Electric Power Survey and Design Institute Co., Ltd., Xinqiaosi Road, Wuhan 430040, China \\ ${ }^{2}$ School of Civil Engineering and Architecture, Wuhan University of Technology, Wuhan 430074, China \\ Correspondence should be addressed to Dong-sheng Xu; dsxu@whut.edu.cn
}

Received 24 April 2021; Accepted 8 July 2021; Published 21 July 2021

Academic Editor: Chia-Huei Wu

Copyright ( $\odot 2021$ Fu-guang Zhu et al. This is an open access article distributed under the Creative Commons Attribution License, which permits unrestricted use, distribution, and reproduction in any medium, provided the original work is properly cited.

\begin{abstract}
The settlement and deformation monitoring for existing tunnels would encounter the difficulties in sensor installation and health evaluation in real time. Thus, it is necessary to develop effective methods for settlement and deformation measurements in the existing tunnels. This study proposed a more practical tunnel deformation monitoring theory and developed remote wireless tunnel deformation real-time monitoring and early warning system based on infrared laser ranging technology and cable sensing technology. The system could monitor the settlement and deformation of the tunnel in real time from a long distance and transmit the deformation data wirelessly in real time; then, three-dimensional space model of tunnel deformation was established, which intuitively and comprehensively reflected the actual deformation of the tunnel and intelligently identified the deformation. Finally, based on the practice of deformation control during tunnel excavation at Xiaohongshu Station of Wuhan Metro Line 8 of China, the measurement results of this new method were compared with the measurement results of particle image velocimetry technology (PIV), the reliability of the new tunnel deformation monitoring method was proved, the settlement error of each monitoring point was found to be less than $1 \mathrm{~mm}$, and the deformation trend was consistent with the actual deformation. The results of this research could provide useful guidance for tunnel deformation monitoring.
\end{abstract}

\section{Introduction}

In recent years, the construction of infrastructures had been further accelerated, and a large number of tunnels had been built. The extrusion of the soil and the surrounding rock mass is the main factor of the deformation. In addition, the mechanical factors in the tunnel will also cause the uneven settlement of the tunnel itself [1]. The initial axial stress of the parallel tunnel can only lead to axial deformation in the section of the entrance, and the axial deformation at the top of the tunnel is in the same direction. Except for the local effect, the axial deformation of other cross sections is 0 , but the area with local effect is the focus of monitoring [2].

Safety accidents caused huge economic property loss, which is caused by tunnel settlement and deformation. Therefore, it was important to monitor of the tunnel during construction and operation. At present, the main domestic tunnel deformation monitoring instruments were electronic total station, laser convergence meter, and traditional steel rule convergence meter. The mentioned various monitoring instruments had high measurement accuracy, but due to their few measurement points, it was impossible to establish a three-dimensional space model of the tunnel, and it was difficult to intuitively and comprehensively reflect the actual deformation of the tunnel. Then, tunnel deformation safety monitoring loopholes were caused. When the tunnel was put into operation, the traditional method no longer meets the actual situation. Therefore, it was necessary to develop a measurement method that could remotely monitor the deformation of the tunnel in real time and directly and comprehensively reflect the deformation state of the tunnel.

Many researchers had carried out a lot of research in the field of tunnel deformation monitoring. Du et al. [3] presented an automated method for tunnel deformation 
monitoring using high-density point clouds data. Xu et al. [4] presented a processing algorithm of the redundant ultrasonic information (RUI) approach, which was proposed to improve measurement accuracy. Xie and Lu [5] developed a new 3D modeling algorithm using Terrestrial Laser Scanning (TLS), which was a newly developed technique that can collect thousands of data points in a few minutes. $\mathrm{Li}$ et al. [6] proposed a new approach using a points-cloud segmentation method based on vectors of neighbor points and surface fitting method based on moving least squares. Chmelina et al. [7] developed the mobile multisensor system for the monitoring and mapping of tunnel walls, and a scan data processing method for the evaluation of 3D tunnel wall displacements from subsequent wall scans. Zhang et al. [8] analyzed the characteristics of the large deformation of the surrounding rock of the tunnel, and the main factors influencing the deformation of the tunnel were revealed. Yang et al. [9] carried out a large-scale model experiment to investigate the convergence deformation and failure characteristics of tunnel boring machine (TBM) excavation surrounding rock in deeply buried composite strata. $\mathrm{Hu}$ et al. [10] established elastoplastic numerical calculation model for three-dimensional finite element for tunnel based on PLAXIS 3D and displacement prediction model for tunnel surrounding rock based on improved grey prediction theory. However, due to the complex geological conditions of the tunnel site, the existing monitoring methods still had technical limitations, such as needs manpower, huge size, and high cost $[11,12]$. It was difficult to obtain a spatial $3 \mathrm{D}$ model of tunnel deformation, especially during the in-service state. The commonly used existing monitoring methods for the deformation and convergence measurement of existing tunnels are summarized in Table 1.

In order to solve the above problems, this study proposed a new tunnel section deformation monitoring method. Compared with other automatic monitoring methods, this intelligent monitoring and early warning system can monitor the deformation in tunnel in real time. The comprehensive analysis of the new method was conducted, from two aspects of data measurement and data processing, and based on the practice of deformation control during tunnel excavation at Xiaohongshu Station of Wuhan Metro Line 8 of China. A more practical tunnel deformation monitoring method was proposed, and three-dimensional space model of tunnel deformation was established, which intuitively and comprehensively reflected the actual deformation of the tunnel. The measurement results of this method were compared with the measurement results of particle image velocimetry technology (PIV); the reliability of the new tunnel deformation monitoring method was proved $[19,20]$. At the same time, based on the tunnel deformation monitoring method, a set of tunnel intelligent monitoring collections system was developed. The system could transmit tunnel deformation data in real time, intelligently identify the tunnel deformation in all directions, and automatically divide the risk level and feedback data to monitoring center. This research provided useful guidance for tunnel excavation and deformation control in the later operation process.

\section{Deformation Monitoring of the Tunnel Model}

2.1. Tunnel Deformation. During the construction and operation of the tunnel, deformation would occur under the action of external forces. Excessive deformation would cause the tunnel to be unusable or even collapse [21]. Tunnel deformation was mainly divided into two types: settlement deformation and convergent deformation, especially when convergent deformation occurs in the tunnel, irregular deformation of the tunnel section will occur, as shown in Figure 1. For the deformation of the tunnel section, it was difficult to achieve comprehensive monitoring using conventional measurement methods. Therefore, it causes great security risks in maintaining the stability of the tunnel. Although three-dimensional laser scanning technology could be used to build a three-dimensional model of the tunnel, the cost of the three-dimensional laser scanning technology was high, and it was difficult to realize real-time monitoring during the operation of the tunnel. In order to solve many problems existing in the existing tunnel monitoring, a brandnew tunnel monitoring scheme was proposed [22].

The tunnel monitoring method used infrared laser rangefinders to realize point-to-point monitoring of the tunnel section. The hardware framework of the intelligent monitoring and early warning system is shown in Figure 2(a). Infrared laser rangefinder and pull-wire convergence instrument form a data acquisition and transmission system, which was mainly responsible for the initial data acquisition, preprocessing, and transmission in the system. The intelligent control warning light integrates the data processing, control system, and the intelligent warning system, and it was mainly responsible for the overall control, data analysis, storage, and early warning work. One intelligent control early warning light could control multiple infrared laser rangefinders and cable convergence devices, which greatly simplifies the operation process and reduces the operating cost of the system.

Figure 2(b) shows a possible field arrangement and measurement situation; the site conditions can be flexibly adjusted and arranged. The infrared laser rangefinders were fixed on the tunnel wall, and multiple rangefinders monitor different measuring points on the same monitoring section [23-25]. Using the measured distance data, infrared laser rangefinder coordinates, and laser angle, the space coordinates of the monitoring point of the monitoring section could be calculated and draw the tunnel section. When the section was deformed, the distance value measured by the infrared laser rangefinder changes, and the coordinates of the monitoring point after deformation can be obtained; then, the deformation curve of the tunnel section was obtained. According to the deformation curve, the risk of tunnel deformation can be predicted in time, and safety measures would be taken in time.

2.2. Tunnel Deformation Monitoring. In order to further study the accuracy of the tunnel section deformation monitoring method, an indoor model test was carried out 
TABLE 1: Features of various deformation monitoring technology.

\begin{tabular}{|c|c|c|c|c|c|c|}
\hline Method & Efficiency & Precision & Application scope & Cost & $\begin{array}{l}\text { Real-time } \\
\text { monitoring }\end{array}$ & Interaction \\
\hline $\begin{array}{l}\text { Automated close-range } \\
\text { photogrammetry [13] }\end{array}$ & Normal & Normal & Section & $\begin{array}{c}\text { Normal (60-180 RMB/ } \\
\mathrm{m})\end{array}$ & Yes & No \\
\hline Measuring robot $[14]$ & $\begin{array}{l}\text { Relatively } \\
\text { high }\end{array}$ & $\begin{array}{l}\text { Relatively } \\
\text { high }\end{array}$ & $\begin{array}{l}\text { Section, critical } \\
\text { area }\end{array}$ & $\begin{array}{c}\text { Normal (75-250 RMB/ } \\
\mathrm{m})\end{array}$ & Yes & No \\
\hline $\begin{array}{l}\text { Automatic hydrostatic leveling } \\
\text { system [15] }\end{array}$ & High & $\begin{array}{l}\text { Relatively } \\
\text { high }\end{array}$ & Only settlement & $\begin{array}{l}\text { Relatively high } \\
(376-450 \mathrm{RMB} / \mathrm{m})\end{array}$ & No & No \\
\hline $\begin{array}{l}\text { Bassett convergence system } \\
{[16]}\end{array}$ & High & Poor & $\begin{array}{l}\text { Medium section, } \\
\text { critical area }\end{array}$ & $\begin{array}{c}\text { Extreme high } \\
(1592-2062 \mathrm{RMB} / \mathrm{m})\end{array}$ & No & No \\
\hline $\begin{array}{l}\text { SOFO and FBG optical fiber } \\
{[17,18]}\end{array}$ & High & High & $\begin{array}{l}\text { Section, critical } \\
\text { area }\end{array}$ & $\begin{array}{l}\text { Normal (190-250 RMB/ } \\
\mathrm{m})\end{array}$ & No & No \\
\hline $\begin{array}{l}\text { Intelligent monitoring and } \\
\text { early warning system }\end{array}$ & High & $\begin{array}{l}\text { Relatively } \\
\text { high }\end{array}$ & $\begin{array}{l}\text { Section, critical } \\
\text { area }\end{array}$ & - & Yes & Yes \\
\hline
\end{tabular}

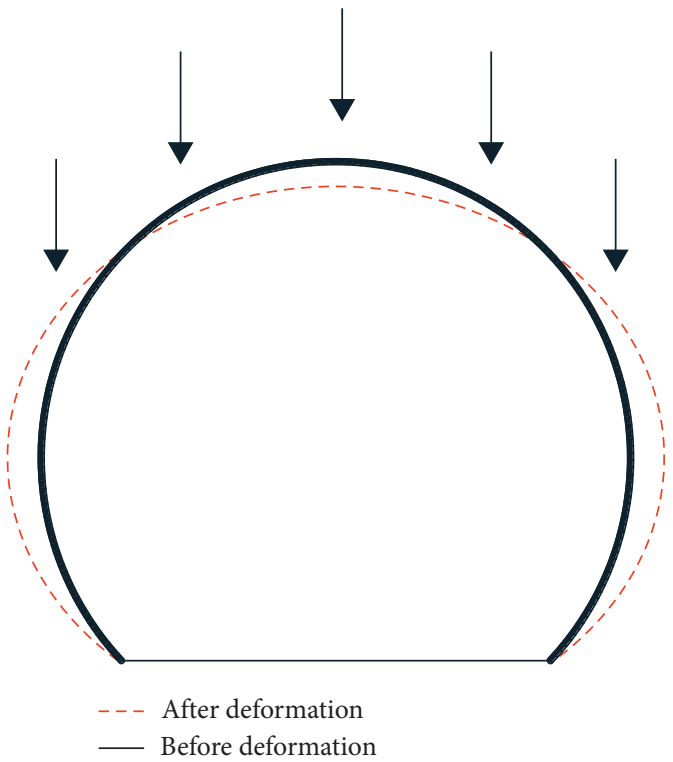

Figure 1: Deformation curve of tunnel section.

[26]. The tunnel section model which is shown in Figure 3 was adopted. The widest was $2.24 \mathrm{~m}$, the distance between the two bases was $1.5 \mathrm{~m}$, and the highest point was $2.1 \mathrm{~m}$ from the ground. The accuracy of the rangefinder's work will be verified by the displacement of three main loading points. During the tunnel deformation, the displacement of other points caused by the uneven settlement of some points will also be reflected in the test results. It showed that No. 1 and No. 3 infrared laser rangefinders were arranged in the plane of the tunnel section model. The laser landing points of the two rangefinders correspond to No. 1 and No. 3 targets, respectively. Taking into account the complex environment of the tunnel site, No. 5 and No. 7 infrared laser rangefinders were arranged outside the plane of the tunnel section model. The laser landing points of the two rangefinders correspond to No. 5 and No. 7 targets, respectively. At the same time, No. 2, No. 4, and No. 6 pull-wire convergence meters were arranged in the plane of the tunnel section model to verify the deformation monitoring results of the infrared laser rangefinder [27].
As shown in Figure 4(a), it was the electronic components that make up the infrared laser rangefinder and the cable convergence instrument. The instruments were mainly composed of sensors (infrared laser sensor and cable sensor), single chip microcomputer, step-down module, communication module, power supply, etc. The range of the infrared laser sensor was $100 \mathrm{~m}$, and the accuracy was $1 \mathrm{~mm}$. The range of the pull-wire sensor was $100 \mathrm{~m}$, and the accuracy was $1 \mathrm{~mm}$; removable rechargeable lithium battery was built in the instruments. Single laser rangefinder needs to collect five valid data for each round of work and transferred the data to intelligent warning indicator light.

Figure 4(b) shows the intelligent warning indicator light, as the data processing and analysis part of the entire system; the indicator light can clearly show the situation of safety monitoring. The indicator light will light up blue when the absolute value of the difference between the measured distance and initial distance of each laser rangefinder is less than $10 \mathrm{~mm}$, and the tunnel is safe; it will light up yellow when the difference is between $10 \mathrm{~mm}$ and $20 \mathrm{~mm}$. When the indicator light is red, it means the absolute value of difference is more than $20 \mathrm{~mm}$, the system will continue to work and if the velocity of deformation is more than $3 \mathrm{~mm} /$ min, all the lights will flash at the same time, and tunnel deformation is very dangerous.

When the system determines the tunnel is safe, the measuring frequency of the laser rangefinder is $1 \mathrm{~h} /$ time; when it lights up yellow, the frequency will increase to $0.5 \mathrm{~h} /$ time; as the red light flashes, the frequency will increase to $1 \mathrm{~min} /$ time. Noticed that due to the interference of construction, once the measurement result changes and stabilizes at smaller deformation, the light will also change to corresponding color.

The calibration results of the self-developed cable sensor and laser sensor are shown in Figure 5. The error distributions of the infrared laser rangefinders were standard normal distribution; pull-wire convergence meters only occurred a limited number of $1 \mathrm{~mm}$ errors in a long time of work.

2.3. Tunnel Deformation Calculation Method. As shown in Figure 6, the spatial rectangular coordinate system was 


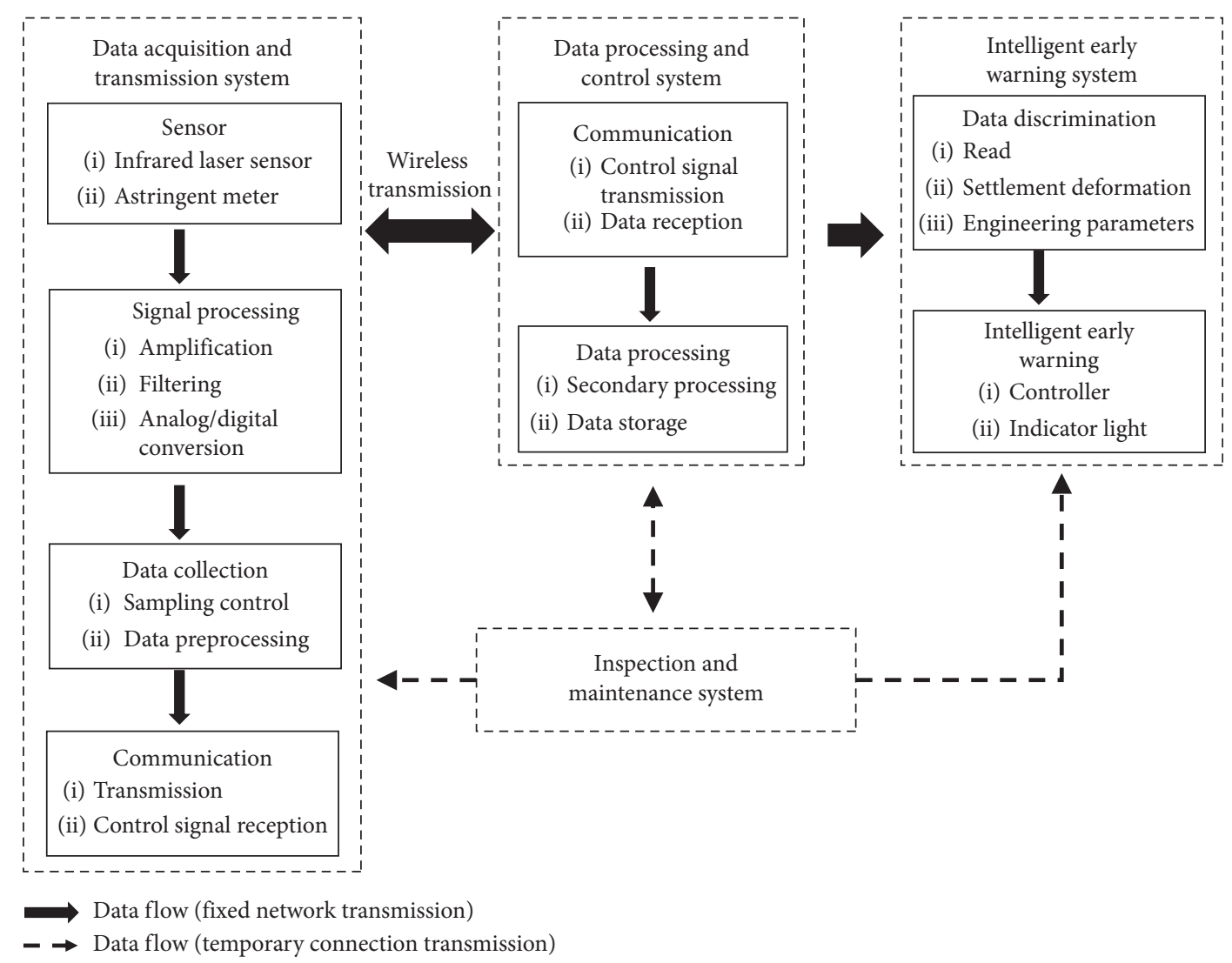

(a)

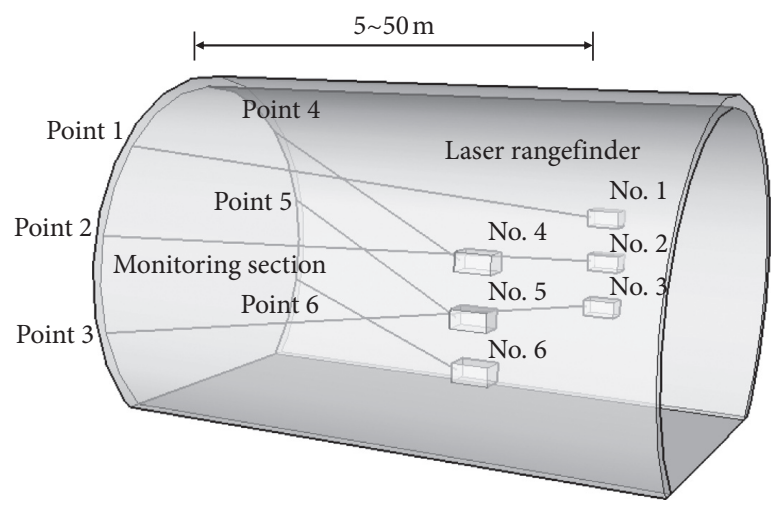

(b)

Figure 2: Intelligent detection and location. (a) Hardware framework of the intelligent monitoring and early warning system. (b) Tunnel section deformation monitoring diagram.

established. The coordinates and elevation angles of the 4 infrared laser rangefinders were recorded, as shown in Table 2. According to the initial measurement results of the infrared laser rangefinder, the initial coordinates of the respective laser landing points could be calculated. After the tunnel model was deformed, the measurement results of the rangefinder would also change. According to the difference between the laser landing point coordinates and the initial coordinates, the deformation of the tunnel could be accurately quantified and the deformation curve of the tunnel model could be drawn.
From the distance and angle relationship between the rangefinder and the target in Figure 6, the coordinates of the laser landing point at each target can be expressed as follows.

The infrared laser rangefinder was in the XZ-plane.

No. 1 target coordinates:

$$
\left(X_{1}+d_{1} \cos \alpha_{1}, 0, d_{1} \sin \alpha_{1}\right) \text {. }
$$

No. 3 target coordinates:

$$
\left(X_{3}-d_{3} \cos \alpha_{3}, 0, d_{3} \sin \alpha_{3}\right) .
$$

The infrared laser rangefinder is out of the $X Z$-plane. 


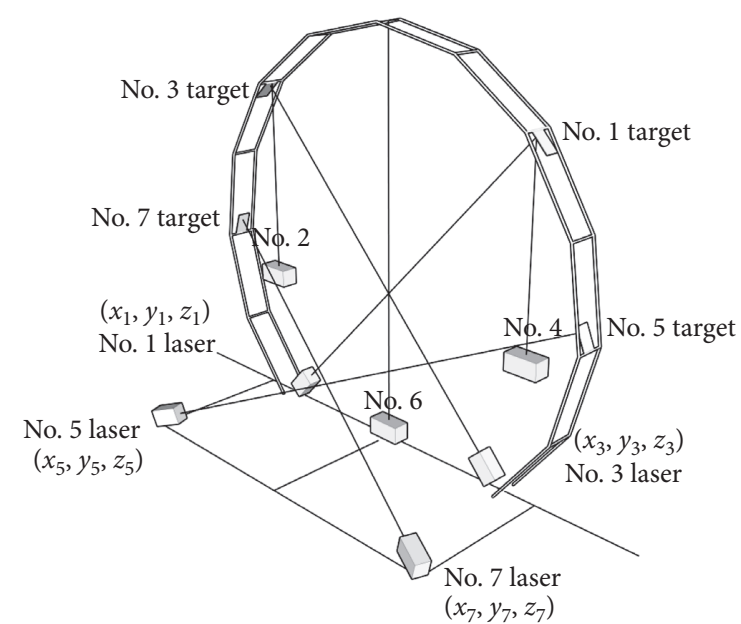

(a)

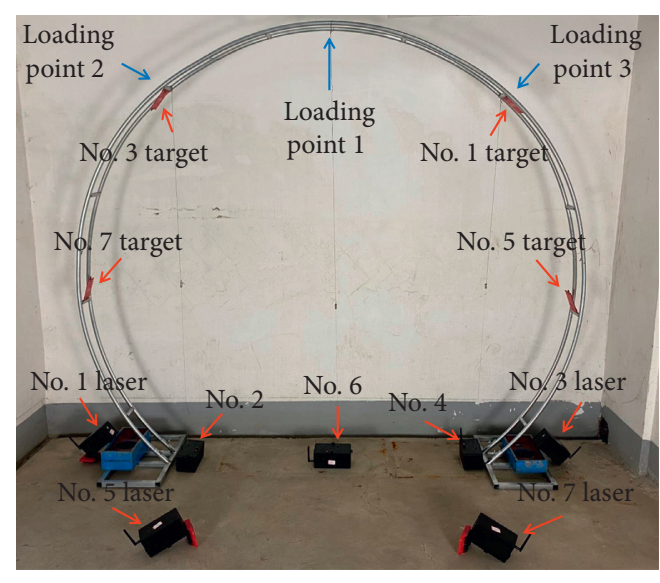

(b)

FIgURE 3: Layout drawing of tunnel model deformation monitoring instrument. (a) Monitoring plan. (b) Test site.

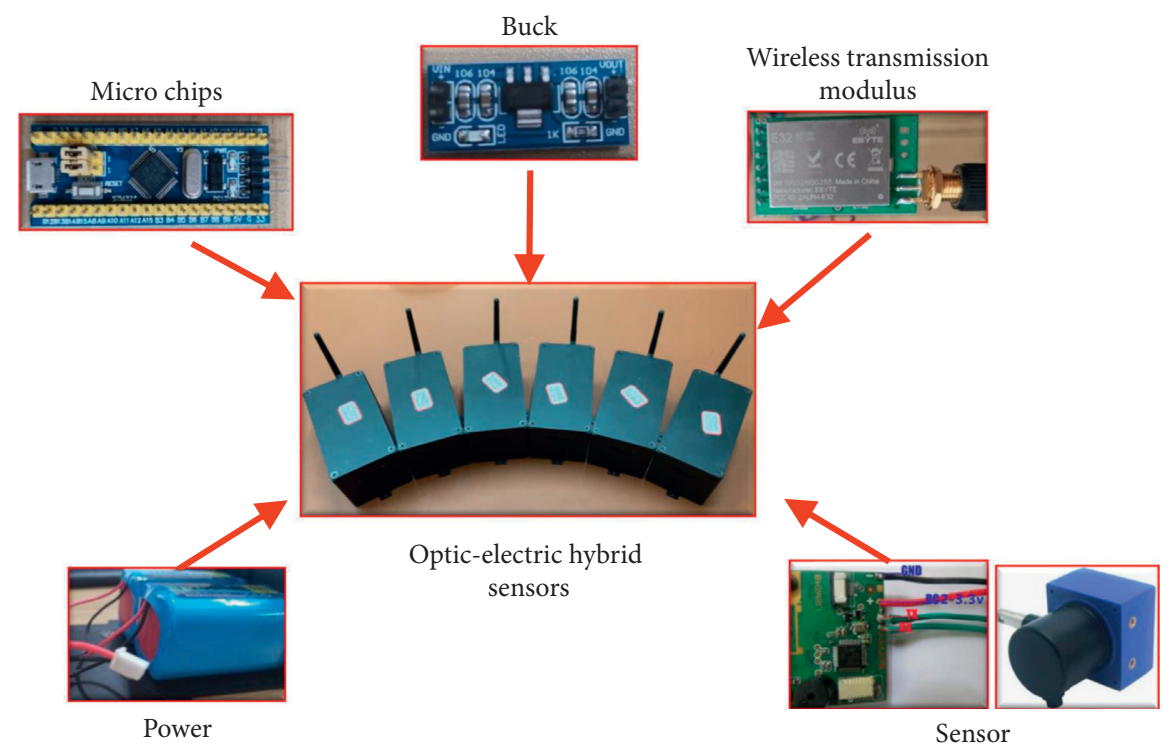

(a)

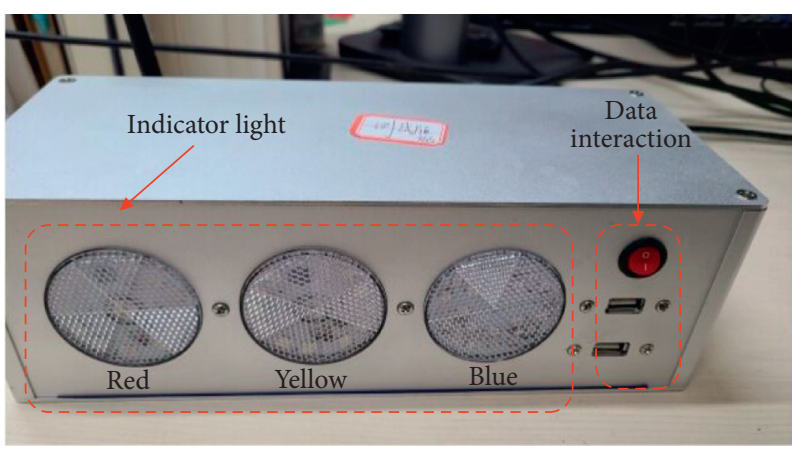

(b)

FIGURE 4: Hardware in the system. (a) Infrared laser rangefinder/cable convergence device. (b) Intelligent warning indicator light. 


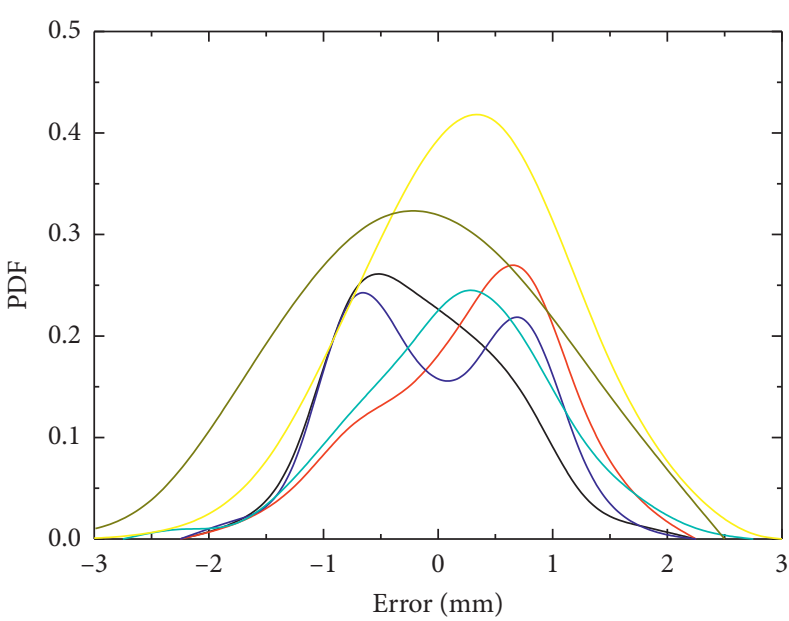

$\begin{array}{lr}\text { No. } 1 \text { laser rangefinder } & \text { No. } 7 \text { laser rangefinder } \\ \text { No. } 3 \text { laser rangefinder } & \text { No. } 9 \text { laser rangefinder } \\ \text { No. } 5 \text { laser rangefinder } & \text { No. } 11 \text { laser rangefinder }\end{array}$

(a)

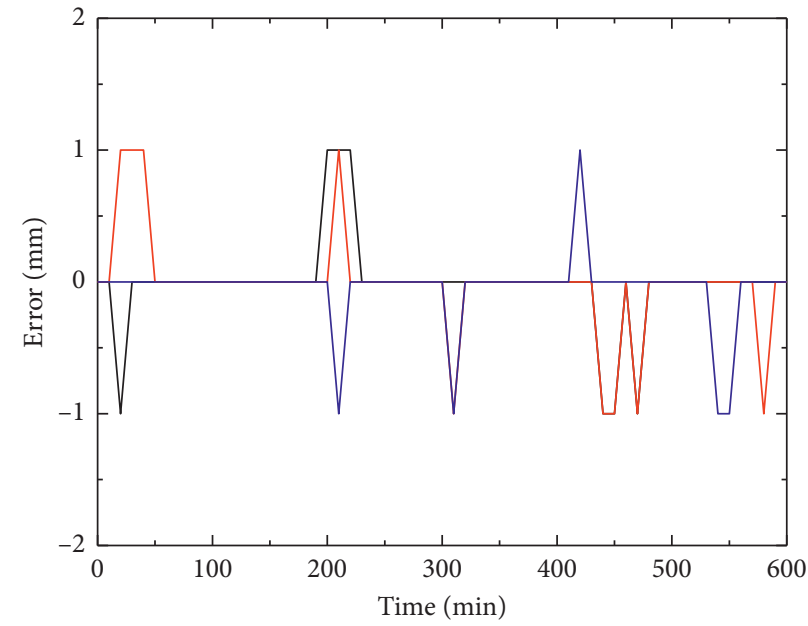

No. 2 pull-wire convergence meters
No. 4 pull-wire convergence meters
No. 6 pull-wire convergence meters

(b)

FIGURE 5: Error of the infrared laser rangefinders and pull-wire convergence meters. (a) PDF of infrared laser rangefinders. (b) Errors of pull-wire convergence meters.

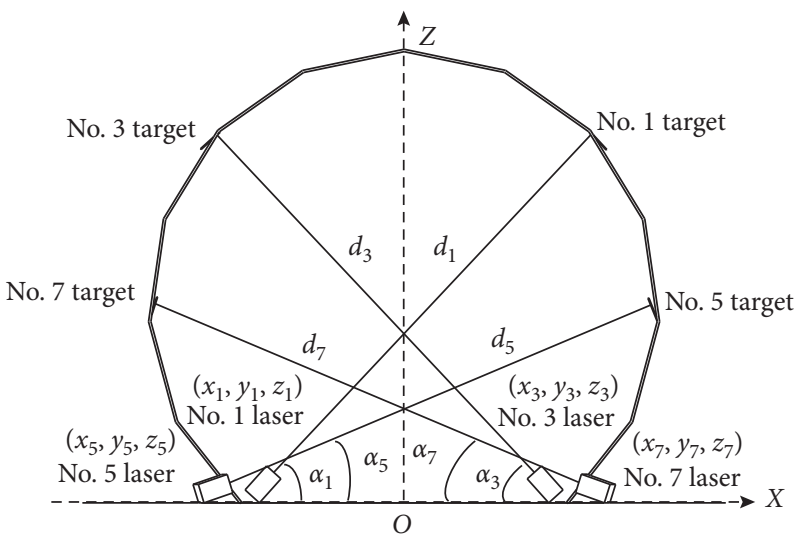

(a)

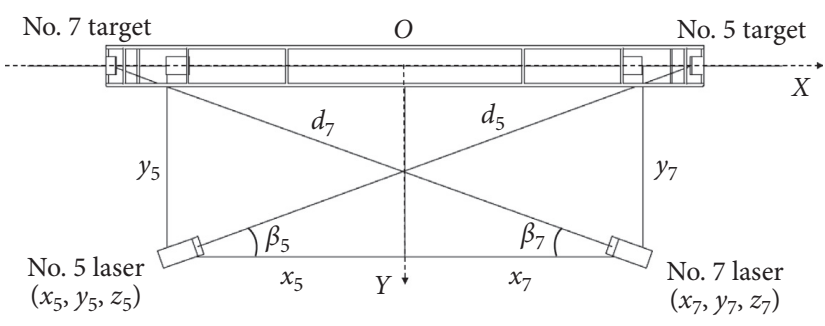

(b)

Figure 6: Tunnel model monitoring diagram. (a) Front view. (b) Top view.

TABLE 2: Initial angle and coordinates of the infrared laser rangefinder.

\begin{tabular}{lccc}
\hline Infrared laser rangefinder & & Angle & Coordinate (m) \\
\hline No. 1 & $\alpha$ & - & $(-1.16,0,0.19)$ \\
No. 3 & 44 & - & $(1.04,0,0.16)$ \\
No. 5 & 45 & 20 & $(-0.64,069,0.13)$ \\
No. 7 & 27 & 20 & $(0.56,0.68,0.12)$ \\
\hline
\end{tabular}

No. 5 target coordinates:

$$
\left(X_{5}+d_{5} \cos \alpha_{5}, y_{5}-d_{5} \cos \alpha \sin \beta_{5}, d_{5} \sin \alpha_{5}\right) \text {. }
$$

No. 7 target coordinates:

$$
\left(X_{7}+d_{7} \cos \alpha, y_{7}-d_{7} \cos \alpha_{7} \sin \beta_{7}, d_{7} \sin \alpha_{7}\right) \text {. }
$$

From equations (1) to (4), the coordinates of the laser landing points of each target are shown in Table 3.

\section{Results Analysis}

3.1. Test Procedure. In order to simulate the actual deformation of the tunnel, the accuracy of the tunnel deformation monitoring method was studied. Add vertical load on the tunnel model; the loading points are shown in Figure 3(b). During the loading process, the sensor was fixed by bolts to ensure that it was in the initial position 
TABLE 3: Initial coordinates of the laser landing point.

\begin{tabular}{lc}
\hline Target & Coordinate $(\mathrm{m})$ \\
\hline No. 1 & $(0.653,0,1.751)$ \\
No. 3 & $(-0.672,0,1.712)$ \\
No. 5 & $(1.214,0.056,0.945)$ \\
No. 7 & $(-1.265,0.066,0.930)$ \\
\hline
\end{tabular}

without displacement or tilt. The $50 \mathrm{~N}$ force will be loaded at loading point 1; after the whole model is stable and enough data is collected, the original $50 \mathrm{~N}$ load is increased to $100 \mathrm{~N}$ and the model is stable and enough data is collected. Repeat the above steps to apply the load to the remaining two loading points.

The deformation tests were carried out with the same boundary conditions. The bottom of the tunnel was fixed in the ground. As indicated in Figure 3, three different points were used to apply stage loads. The deformation of the model was measured at different load conditions. The deformation measured by the PIV was then compared with the results of the proposed sensors. The experimental tests would simulate the in-situ conditions in which the central load reflected the tunnel experienced overburden earth pressure. The eccentric loads of loading point 2 and 3 can simulate the nonuniform earth pressure of surrounding soils.

3.2. Test Results. During the tests, 6 kinds of working conditions were loaded. In order to improve the accuracy of the experimental data, the infrared laser rangefinder was used to measure twice in succession to take the average value; then, the coordinate of the landing point of each laser was calculated by equation 1 to equation 4 . Table 4 shows the displacement of each monitoring point under the 6 working conditions.

Table 4 shows the load was carried out at No. 1 position. The displacement of No. 1 target and No. 3 target monitoring point was symmetrical, which was consistent with the theoretical displacement. When $50 \mathrm{~N}$ was loaded, the displacement of No. 5 target and No. 7 target was $1 \mathrm{~mm}$; when $100 \mathrm{~N}$ was loaded, the displacement of No. 5 target and No. 7 target was $2 \mathrm{~mm}$; when $50 \mathrm{~N}$ and $100 \mathrm{~N}$ were loaded at point 2 , the sinking at the monitoring point of target No. 3 were $7 \mathrm{~mm}$ and $11 \mathrm{~mm}$, respectively; when $50 \mathrm{~N}$ and $100 \mathrm{~N}$ were loaded at point 3, the sinking at the monitoring point of target No. 1 was $5 \mathrm{~mm}$ and $9 \mathrm{~mm}$, respectively. It could be seen from the monitoring results that during the loading process, the monitoring point on the tunnel model had a slight displacement in the $Y$-direction; these minor errors were due to the incomplete symmetry of the tunnel model, or deviation of load application direction and theoretical application direction.

As shown in Table 5, it was the sinking of each measuring point measured by the cable convergence instrument. As shown in Figure 7, according to the displacement calculation results of each monitoring point, the tunnel model deformation curves were drawn. The displacement
TABLE 4: Loading displacement of each measuring point of the infrared laser rangefinder.

\begin{tabular}{lcccc}
\hline \multirow{2}{*}{ Loading method } & Target & \multicolumn{3}{c}{ Displacement (m) } \\
& & $X$ & $Y$ & $Z$ \\
\hline \multirow{4}{*}{ Loading point 1 50 N } & 0.003 & 0.000 & -0.003 \\
& No. 3 & -0.003 & 0.000 & -0.003 \\
& No. 5 & 0.002 & 0.000 & -0.001 \\
& No. 7 & -0.003 & 0.001 & -0.002 \\
\hline & No. 1 & 0.005 & 0.000 & -0.005 \\
Loading point 1 100 N & No. 3 & -0.005 & 0.000 & -0.005 \\
& No. 5 & 0.003 & 0.001 & -0.002 \\
& No. 7 & -0.005 & 0.002 & -0.002 \\
\hline & No. 1 & 0.001 & 0.000 & -0.001 \\
Loading point 2 50 N & No. 3 & -0.007 & 0.000 & -0.007 \\
& No. 5 & 0.001 & 0.000 & 0.000 \\
& No. 7 & -0.006 & 0.002 & -0.003 \\
\hline & No. 1 & 0.002 & 0.000 & -0.002 \\
Loading point 2 100 N & No. 3 & -0.011 & 0.000 & -0.011 \\
& No. 5 & 0.002 & 0.001 & -0.001 \\
& No. 7 & -0.010 & 0.003 & -0.005 \\
\hline & No. 1 & 0.005 & 0.000 & -0.005 \\
Loading point 3 50N & No. 3 & -0.001 & 0.000 & -0.001 \\
& No. 5 & 0.006 & 0.002 & -0.003 \\
& No. 7 & 0.000 & 0.000 & 0.000 \\
\hline & No. 1 & 0.009 & 0.000 & -0.009 \\
Loading point 3 100 N & No. 3 & -0.002 & 0.000 & -0.002 \\
& No. 5 & 0.010 & 0.003 & -0.005 \\
& No. 7 & -0.002 & 0.000 & -0.001 \\
\hline & & & &
\end{tabular}

at the monitoring point was enlarged by 20 times to more intuitively reflect the deformation of the tunnel model before and after loading.

From the perspective of the deformation trend of the tunnel model, the deformation of the tunnel model under various working conditions roughly conformed to the laws of mechanics, and the new tunnel deformation monitoring method could effectively and intuitively reflect the deformation of the tunnel and then improve the ability to identify tunnel deformation risks.

As shown in Table 6, the measured values of infrared laser rangefinder No.1 and No.3 were compared with the values measured by the cable convergent instrument. From the results in the table, it could be seen that the two types of measuring instruments have monitored the subsidence error within $1 \mathrm{~mm}$, which fully demonstrates the reliability of the tunnel deformation calculation method using the measured data of the infrared laser rangefinder.

\section{PIV Monitoring}

Particle image velocimetry technology (PIV) was a fluid dynamics velocimetry method that can perform transient capture, multipoint tracking, and noncontact [28]. In this study, the PIV technology was used to capture the state before and after the deformation of the tunnel model and perform image processing to obtain the displacement value of each observation point on the tunnel model. At the same time, the displacement values 
TABLE 5: Measured value of the cable convergence instrument.

\begin{tabular}{lccr}
\hline Loading method & & Convergence meter data $(\mathrm{m})$ & No. 4 \\
& No. 2 & 0.996 & No. 6 \\
\hline Initial state & 0.996 & 0.992 & 0.881 \\
Loading point 1 $50 \mathrm{~N}$ & 0.993 & 0.991 & 0.870 \\
Loading point 1 $100 \mathrm{~N}$ & 0.991 & 0.995 & 0.863 \\
Loading point 2 $50 \mathrm{~N}$ & 0.990 & 0.994 & 0.878 \\
Loading point 2 $100 \mathrm{~N}$ & 0.985 & 0.990 & 0.875 \\
Loading point 3 $50 \mathrm{~N}$ & 0.995 & 0.986 & 0.875 \\
Loading point 3 $100 \mathrm{~N}$ & 0.993 & 0.871 \\
\hline
\end{tabular}

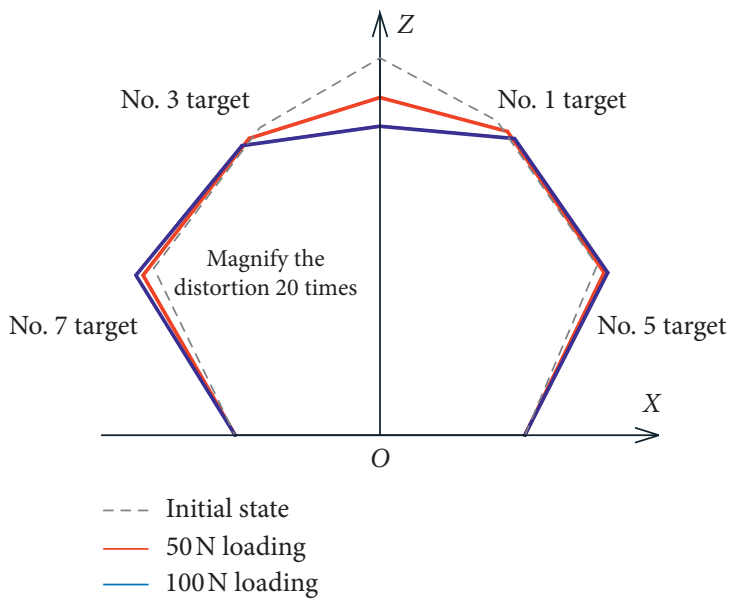

(a)

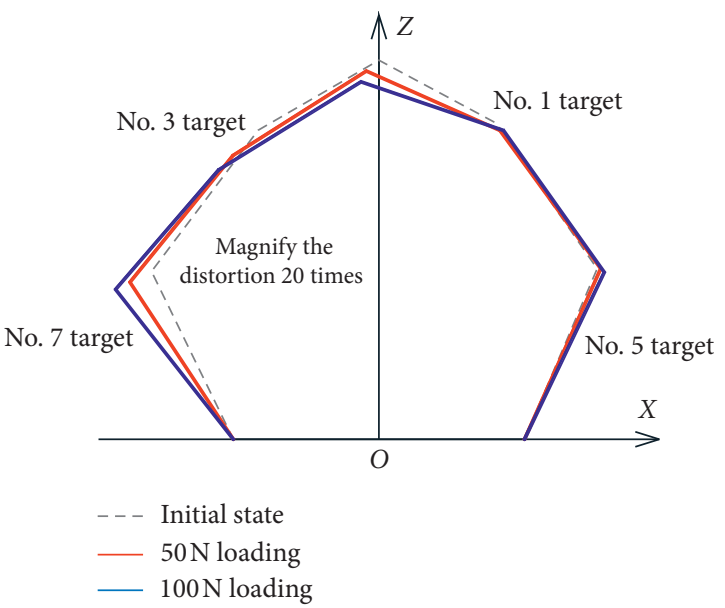

(b)

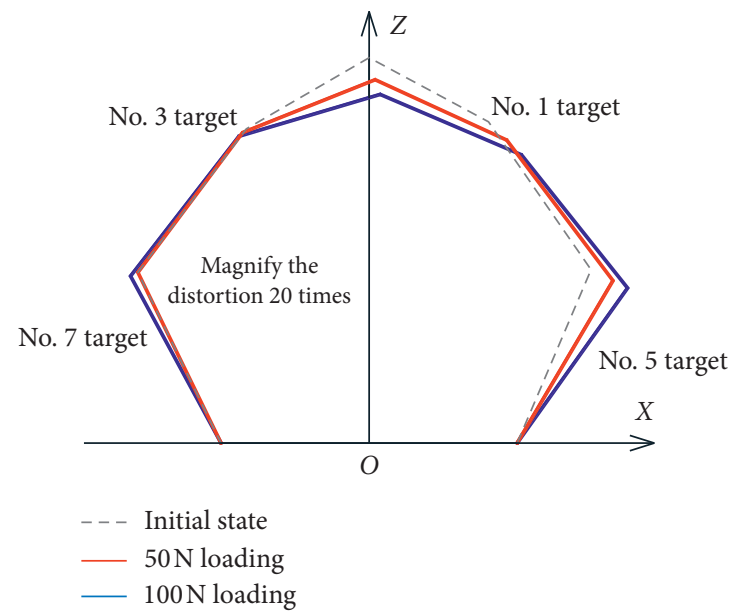

(c)

Figure 7: Loading deformation curve. (a) Point 1. (b) Point 2. (c) Point 3.

of the observation point measured by this technology were compared with the deformation displacement of the tunnel calculated by the measurement data of the infrared laser rangefinder. As shown in Figure 7, it was the erection of the industrial camera during the experiment.

As shown in Figure 8, the industrial camera is set on the front of the model. By setting the acquisition frequency, the deformation of the model in the whole experiment is monitored. When the tunnel is deformed, the industrial camera will record the displacement of each point in the picture. Through MATLAB analysis, the displacement of each point can be obtained under the condition that the field scale has been corrected.

As shown in Figures 9(a) and 9(b), it was the total displacement nephogram of PIV when loading at No. 1 loading point. From the displacement nephogram, it could be seen that the total displacement of the top was $8 \mathrm{~mm}$ and $15 \mathrm{~mm}$ during the first and second loading, respectively, which was $1 \mathrm{~mm}$ different from the displacement data 
TABLE 6: Comparison of sinking values measured with the infrared laser rangefinder and pull-wire sensor.

\begin{tabular}{|c|c|c|c|}
\hline \multirow{2}{*}{ Load force } & \multirow{2}{*}{ Target } & \multicolumn{2}{|c|}{ Displacement $Z(\mathrm{~m})$} \\
\hline & & Infrared laser rangefinder & Convergence meter \\
\hline \multirow{2}{*}{ Point $150 \mathrm{~N}$} & No. 1 & -0.003 & -0.004 \\
\hline & No. 3 & -0.003 & -0.003 \\
\hline \multirow{2}{*}{ Point $1100 \mathrm{~N}$} & No. 1 & -0.005 & -0.006 \\
\hline & No. 3 & -0.005 & -0.005 \\
\hline \multirow{2}{*}{ Point $250 \mathrm{~N}$} & No. 1 & -0.001 & -0.001 \\
\hline & No. 3 & -0.007 & -0.006 \\
\hline \multirow{2}{*}{ Point $2100 \mathrm{~N}$} & No. 1 & -0.002 & -0.002 \\
\hline & No. 3 & -0.011 & -0.011 \\
\hline \multirow{2}{*}{ Point $350 \mathrm{~N}$} & No. 1 & -0.005 & -0.006 \\
\hline & No. 3 & -0.001 & -0.001 \\
\hline \multirow{2}{*}{ Point $4100 \mathrm{~N}$} & No. 1 & -0.009 & -0.010 \\
\hline & No. 3 & -0.002 & -0.003 \\
\hline
\end{tabular}

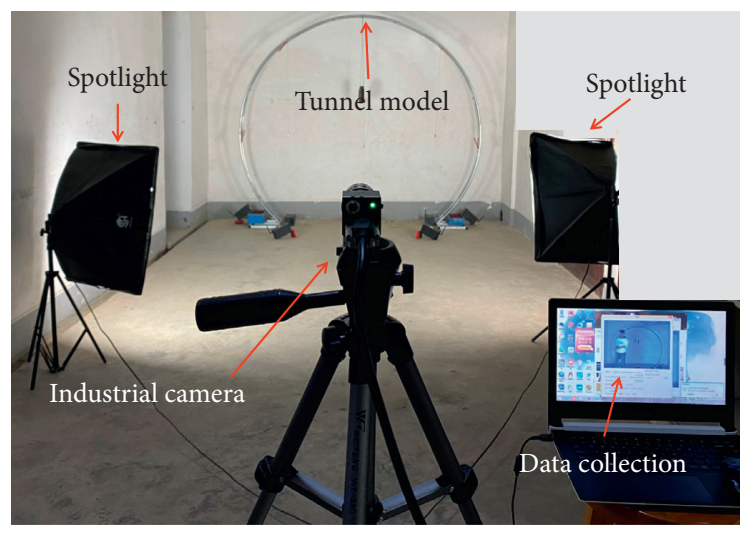

FIgURE 8: The erection of the PIV industrial camera.

measured by the cable convergence instrument. The displacement data of the remaining monitoring points were roughly consistent with the tunnel deformation calculated by the infrared laser rangefinder. It could be seen from the displacement nephogram that the left and right displacements of the tunnel model were roughly symmetrical, which was consistent with the force of the model.

As shown in Figures 9(c) and 9(d), it was the total displacement nephogram of PIV when loading at No. 2 loading point. From the displacement nephogram, it could be seen that the total displacement of the top was $3 \mathrm{~mm}$ and $6 \mathrm{~mm}$ during the first and second loading, respectively, which was consistent with the displacement data measured by the cable convergence instrument. It could be seen from the displacement nephogram that the displacement on the left side of the model was relatively large, and the displacement on the right side was close to 0 , which was consistent with the deformation law of the loading deformation curve at point 2 in Figure 7(b).

As shown in Figures 9(e) and 9(f), it was the total displacement nephogram of PIV when loading at No. 3 loading point. From the displacement nephogram, it could be seen that the total displacement of the top was $7 \mathrm{~mm}$ and $11 \mathrm{~mm}$ during the first and second loading, respectively, which was consistent with the displacement data measured by the cable convergence instrument. It could be seen from the displacement nephogram that the displacement on the right side of the model was large, and the displacement on the left side was close to 0 , which was consistent with the deformation law of the loading deformation curve at point 3 in Figure 7(c).

It could be seen from the symmetry that theoretically the displacement nephogram loaded at point 2 and the displacement nephogram loaded at point 3 should be antisymmetric. However, as compared with the measured displacement results, the displacement nephogram of the tunnel under applied loads at point 2 was different from that at point 3 . Thus, the offset of load direction would result in the variation of tunnel deformations.

As shown in Table 7, the deformation data of the tunnel model were monitored by the PIV technology, of which 14 PIV monitoring deformation data were completely consistent with the tunnel deformation calculated by the infrared laser rangefinder measurement data, and the errors of the 16 monitoring data were not more than $1 \mathrm{~mm}$. The comparison with the PIV technology monitoring data further proved the accuracy of the tunnel deformation method calculated by the infrared laser rangefinder measurement data.

\section{Field Application}

5.1. Project Overview. The total length of the section from Hongshan Road Station to Xiaohongshu Station in the second phase of Metro Line 8 was 1586.9 meters. The sections were constructed by shield tunneling method, large-section mining method, and small-section mining method. In this project, the large-section mining method tunnel was 109 meters in length, 20.14 meters wide, and 12.83 meters high, with an area of 258.40 square meters, and the remaining parts were constructed by the small-section method. It was currently the largest subway tunnel excavation section in Wuhan, China, as shown in Figure 10. The large-section tunnel was located in a karst area. In order to ensure the safety of the tunnel construction, the project department used the double-side-side pilot tunnel method to excavate the tunnel into three pilot tunnels on the left, center, and right; the secondary lining adopts full scaffolding, mould arch, and 


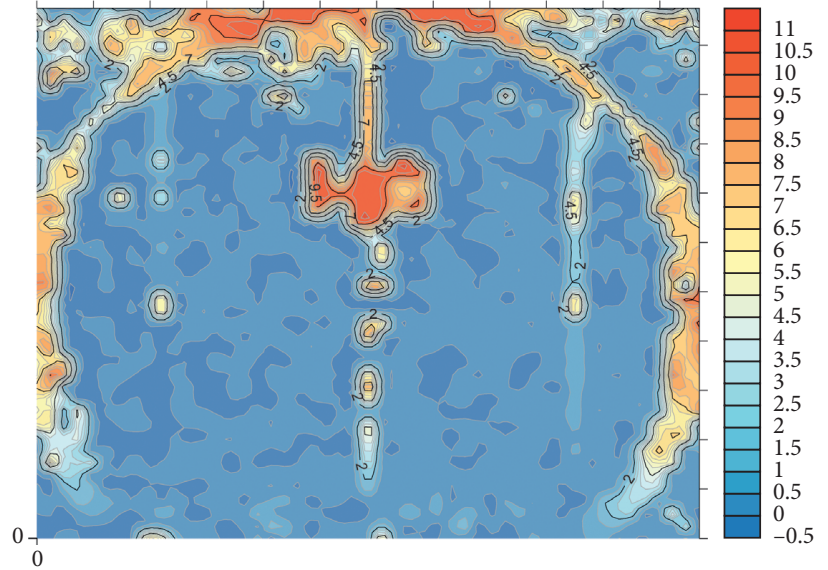

(a)

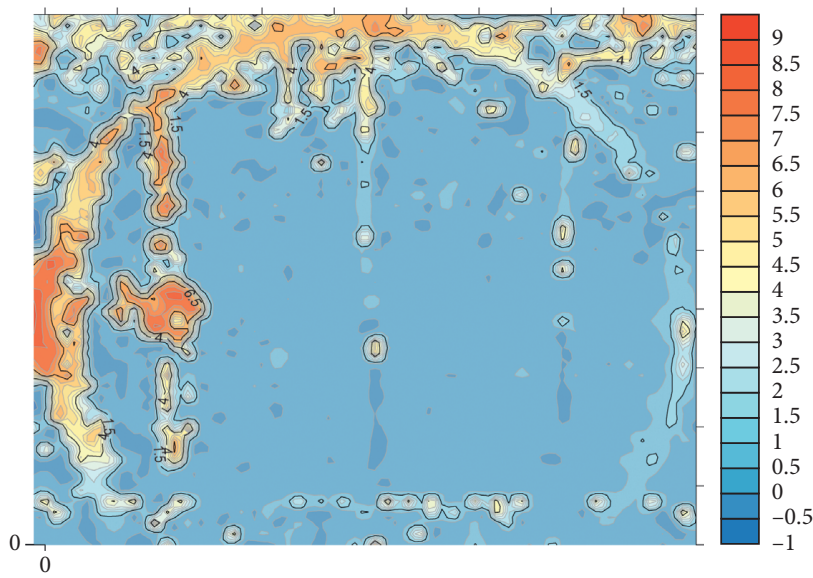

(c)

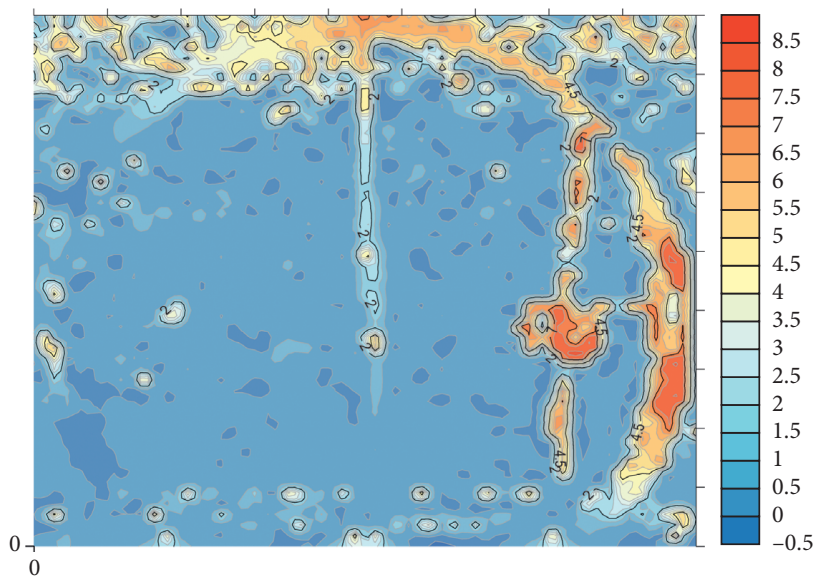

(e)

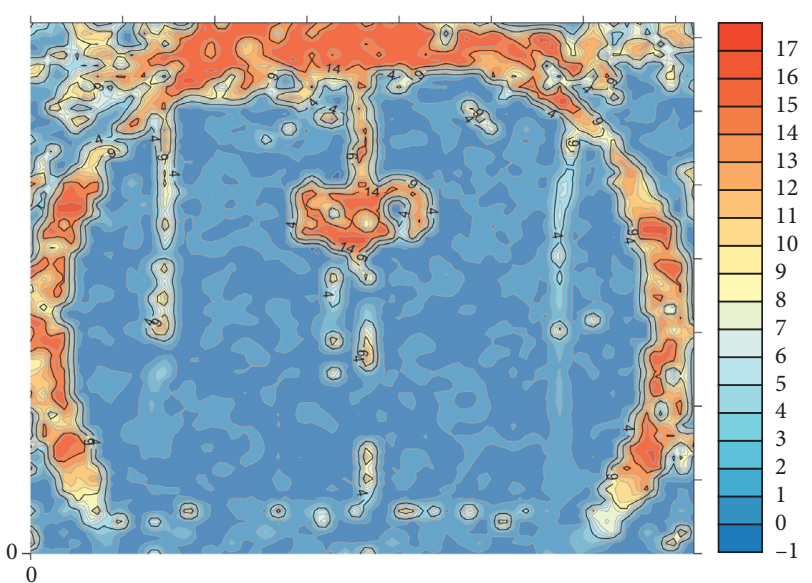

(b)

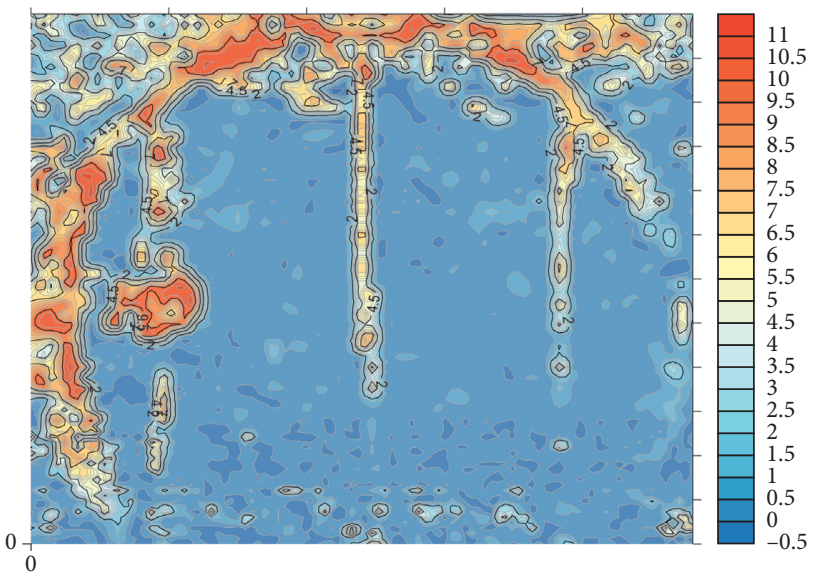

(d)

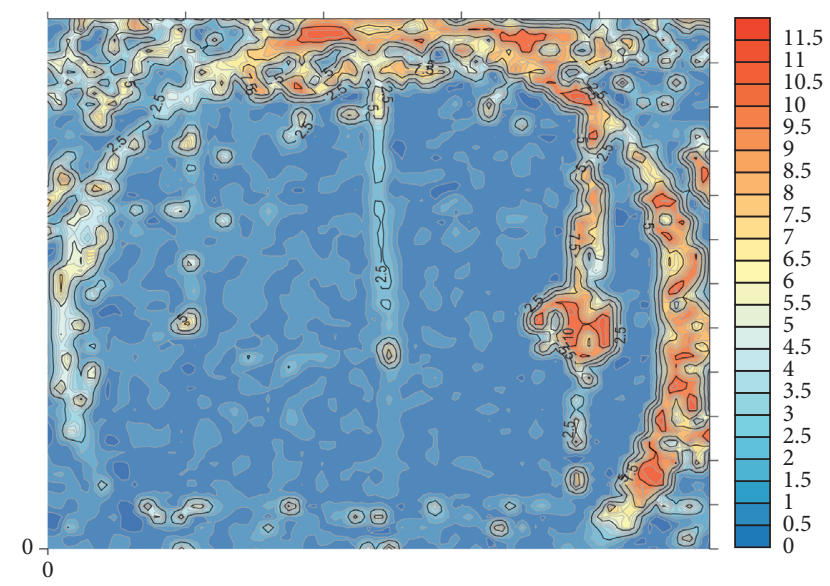

(f)

FIgURE 9: PIV total displacement nephogram. (a) First-level loading at point 1. (b) Second-level loading at point 1. (c) First-level loading at point 2. (d) Second-level loading at point 2. (e) First-level loading at point 3. (f) Second-level loading at point 3.

small formwork construction. Geological radar was used to detect surrounding rock conditions in advance and carry out drilling and grouting in advance for karst. As shown in Figure 10, it was the construction site of the tunnel at Xiaohongshu station. Due to accounting the complexity of the tunnel site environment and combining the characteristics of the tunnel deformation monitoring system, a monitoring program based on infrared laser rangefinder and cable convergence meter was proposed.

In this project, the position of the sensor was specifically designed. The system centrally controls the sensor work of the required monitoring part through the intelligent warning light. Through the monitoring standard set in Section 2.2, the tunnel deformation is monitored in real time. 
TABLE 7: Comparison of PIV monitoring displacement and new monitoring method calculation displacement.

\begin{tabular}{|c|c|c|c|c|c|}
\hline \multirow{2}{*}{ Loading method } & \multirow{2}{*}{ Target } & \multicolumn{2}{|c|}{ Displacement $X(\mathrm{~mm})$} & \multicolumn{2}{|c|}{ Displacement $Z(\mathrm{~m})$} \\
\hline & & New method & PIV & New method & PIV \\
\hline \multirow{5}{*}{ Loading point $150 \mathrm{~N}$} & No. 1 & 3 & 3 & -3 & -3 \\
\hline & No. 3 & -3 & -3 & -3 & -3 \\
\hline & No. 5 & 2 & 3 & -1 & -2 \\
\hline & No. 7 & -3 & -3 & -2 & -3 \\
\hline & Point 1 & - & - & -9 & -8 \\
\hline \multirow{5}{*}{ Loading point $1100 \mathrm{~N}$} & No. 1 & 5 & 6 & -5 & -5 \\
\hline & No. 3 & -5 & -6 & -5 & -5 \\
\hline & No. 5 & 3 & 3 & -2 & -2 \\
\hline & No. 7 & -5 & -5 & -2 & -2 \\
\hline & Point 1 & - & - & -16 & -15 \\
\hline \multirow{5}{*}{ Loading point $250 \mathrm{~N}$} & No. 1 & 1 & 1 & -1 & -1 \\
\hline & No. 3 & -7 & -8 & -7 & -7 \\
\hline & No. 5 & 1 & 1 & 0 & 1 \\
\hline & No. 7 & -6 & -6 & -3 & -3 \\
\hline & Point 1 & - & - & -3 & -3 \\
\hline \multirow{5}{*}{ Loading point $2100 \mathrm{~N}$} & No. 1 & 2 & 2 & -2 & -2 \\
\hline & No. 3 & -11 & -10 & -11 & -11 \\
\hline & No. 5 & 2 & 2 & -1 & -2 \\
\hline & No. 7 & -10 & -10 & -5 & -5 \\
\hline & Point 1 & - & - & -6 & -6 \\
\hline \multirow{5}{*}{ Loading point $350 \mathrm{~N}$} & No. 1 & 5 & 6 & -5 & -5 \\
\hline & No. 3 & -1 & -1 & -1 & -1 \\
\hline & No. 5 & 6 & 6 & -3 & -3 \\
\hline & No. 7 & 0 & -1 & 0 & -1 \\
\hline & Point 1 & - & - & -6 & -7 \\
\hline \multirow{5}{*}{ Loading point $3100 \mathrm{~N}$} & No. 1 & 9 & 10 & -9 & -9 \\
\hline & No. 3 & -2 & -2 & -2 & -2 \\
\hline & No. 5 & 10 & 9 & -5 & -6 \\
\hline & No. 7 & -2 & -2 & -1 & -1 \\
\hline & Point 1 & - & - & -10 & -11 \\
\hline
\end{tabular}

5.2. Tunnel Intelligent Monitoring Collection System. The monitoring system installed is mainly located in the shield tunnel section of Xiaohongshu Station, and the support has just been completed. According to the research of Peng et al. [29], the longitudinal deformation of subsidence caused by tunnel excavation itself and the influence on the tunnel during the later construction need real-time warning from the monitoring system. Long-term monitoring of the tunnel in the later stage and even in the operational phase should also be considered. Based on the above considerations, the intelligent early warning and monitoring system proposed in this paper plays an important role in the construction of the tunnel.

Shield tunneling is an effective and economical method for tunnel construction under various geological conditions. Long-term deformation of shield tunnel may lead to groundwater leakage inside the tunnel [30]. Whether it is natural deformation that causes changes in the water table, or artificial excavation and development of urban underground space construction, even used the APRS (automatic pumping-recharge system) [31], groundwater changes still have a significant impact on tunnel. Many researchers investigated that the deformation caused by groundwater is irreversible and has an influence on the shield process and later operation. The corresponding monitoring and numerical simulation methods are also studied [32]. The intelligent monitoring system proposed in this paper will monitor the deformation of tunnel for a long time.

The intelligent control warning light was mainly composed of single-chip microcomputer, timing module, indicator module, power supply module, step-down module, communication module, and memory. It was used to remotely control the working status of the test instrument at the tunnel site. Intelligent control warning light receives and stores the distance data from the test instrument and turns on the hazard warning lights according to the settlement and deformation of the tunnel site: blue light, yellow light, and red light. The built-in uninterruptible power supply can access to $220 \mathrm{~V}$ AC power supply. After the power was turned on, the intelligent control warning light transmitted signals to the infrared laser rangefinder and the cable convergence device. Each instrument entered the ranging mode in turn. After the ranging was completed, the laser rangefinder entered the sleep mode until the next time it was activated. In the same way, the intelligent control warning light transmitted the signal to the cable convergence meter, the cable convergence meter entered the ranging mode and transmitted the data at this time to the memory storage in the intelligent control warning light. After the ranging was finished, the laser rangefinder entered the sleep mode, until the next time it was activated. 


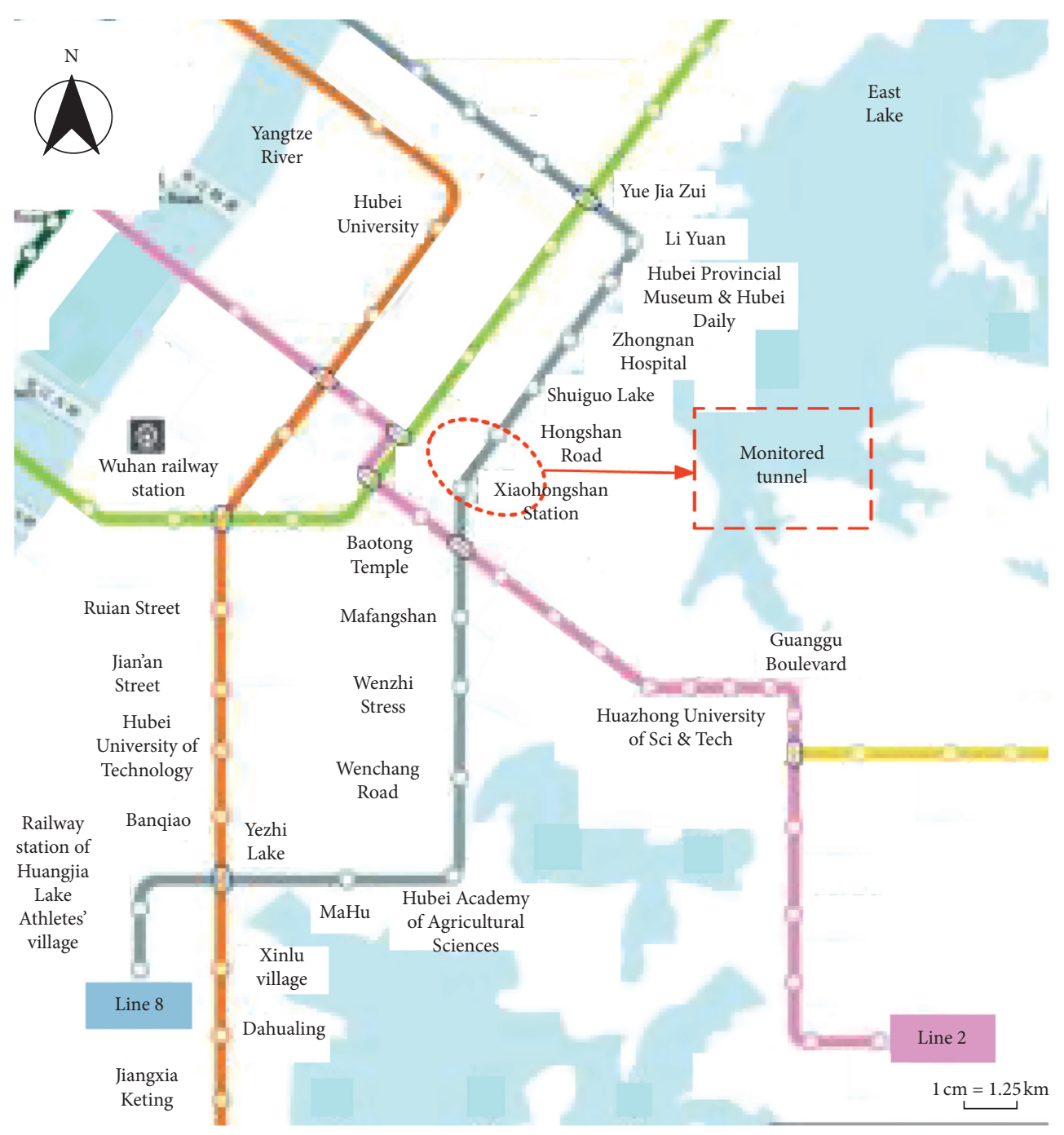

(a)

Figure 10: Continued. 


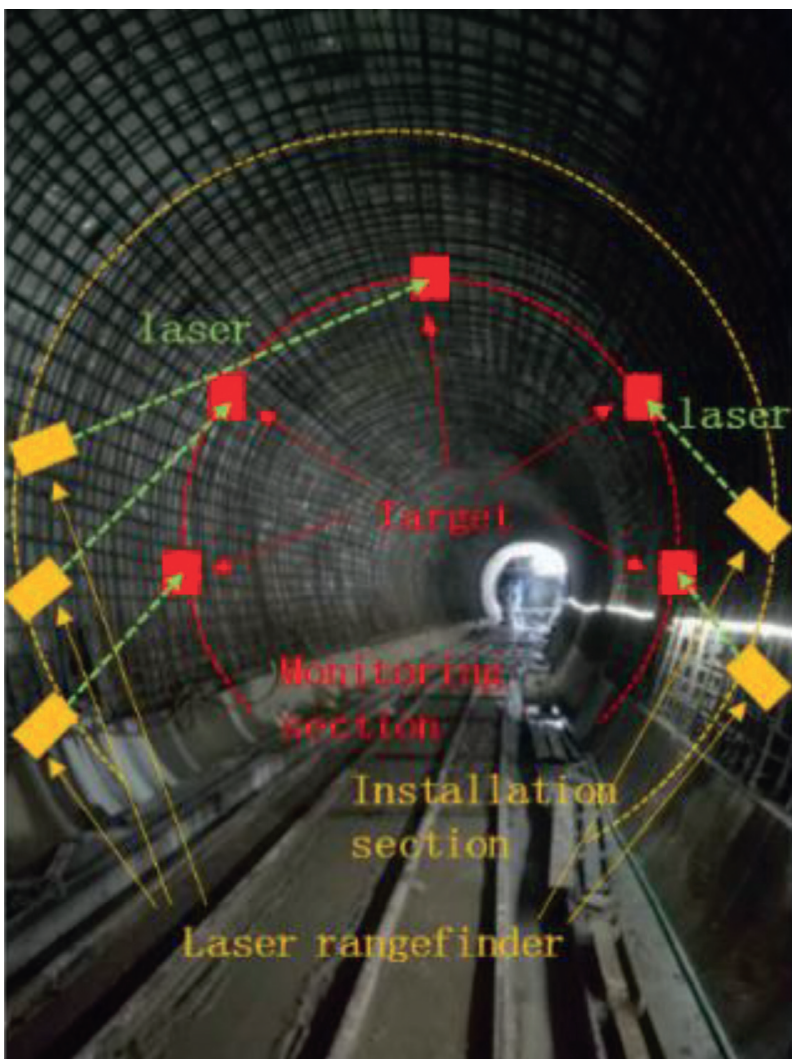

(b)

Figure 10: Xiaohongshu Station Tunnel Construction Site, Wuhan, China. (a) Wuhan railway station topology of the project site. (b) Xiaohongshu Station Tunnel site.

Using the tunnel intelligent monitoring and acquisition system, according to the layout shown in Figure 10(b), multiple infrared laser rangefinders, pull-wire convergence meters, and measurement targets were arranged at key sections of the tunnel $[33,34]$. According to the initial installation parameters and the initial ranging readings of each instrument, a spatial coordinate system was established, and the initial coordinates of each point was recorded. The relative displacement between various points was monitored by instruments; the deformation of the tunnel section was monitored in real time. The deformation curve of the tunnel section was obtained, and the safety index of the tunnel was evaluated. At the same time, when the deformation of the tunnel section was too large, the intelligent control warning light could be used for warning according to the built-in warning rules, which greatly protected the safety of life and property.

\section{Conclusions}

Based on the existing tunnel settlement and deformation monitoring methods, this paper combined with the site conditions during tunnel construction and operation and considered the advantages and disadvantages of various monitoring methods. Then, a set of more practical tunnel deformation monitoring methods were proposed. The remote wireless tunnel deformation real-time monitoring and early warning system based on infrared laser ranging technology was proposed. It provided useful guidance for tunnel excavation and deformation control in the operation process and had great engineering practical value. This article drew the following conclusions:

(1) A more practical tunnel deformation monitoring method was proposed, which can effectively and intuitively reflect the deformation of the tunnel. The deformation state of the tunnel section was displayed in three dimensions; the ability to identify risk of tunnel deformation was improved. The measurement results of this method were compared with the displacement nephogram of tunnel model which was obtained by PIV technology; the reliability of the new tunnel deformation monitoring method was further proved.

(2) Through the intelligent control system, it was possible to realize real-time collection of measuring point data, real-time wireless transmission, storing data, and timely analysis of monitoring data. The intelligent system can realize real-time monitoring of tunnel settlements and deformations. Thus, it could greatly improve the safety of subway tunnels.

(3) The monitoring system was simple to operate, easy to install, and relatively of low cost. It had good applicability during tunnel construction and operation. The monitoring system could effectively monitor settlement and deformation of subway tunnels, 
which could be of benefit to the health monitoring of tunnels in service.

\section{Data Availability}

The data used to support the findings of this study are available from the corresponding author upon request.

\section{Conflicts of Interest}

The authors declare that they have no conflicts of interest regarding the publication of this paper.

\section{Acknowledgments}

Financial support for this work was jointly provided by the National Natural Science Foundation of China (Grant no. 41972271), the Fundamental Research Funds for Central Universities of China (Grant no. 3120620191), and Sanya Science and Education Innovation Park of Wuhan University of Technology (Project no. 2020KF0007).

\section{References}

[1] G. Y. Hou, L. Z. Xiang, T. Hu et al., "Study of tunnel settlement monitoring based on distributed potic fiber strain sensing technology," Rock and Soil Mechanics, vol. 41.

[2] X. R. Ge, "The study on the mechanism of the longitudinal deformation of tunnel due to excavation," Rock and Soil Mechanics, vol. 13, no. 3, pp. 80-89, 1992.

[3] L. Du, R. Zhong, H. Sun, and Q. Wu, "Automatic monitoring of tunnel deformation based on high density point clouds data," ISPRS International Archives of the Photogrammetry, vol. 353, no. 7, pp. 353-360, 2017.

[4] D. S. Xu, Y. M. Zhao, H. B. Liu, and H. H. Zhu, "Deformation monitoring of metro tunnel with a new ultrasonic-based system," Sensors, vol. 17, no. 8, p. 1758, 2017.

[5] X. Y. Xie and X. Z. Lu, "Development of a 3D modeling algorithm for tunnel deformation monitoring based on terrestrial laser scanning," Underground Space, vol. 2, no. 1, pp. 16-29, 2017.

[6] J. Li, Y. Wan, and X. Gao, "A new approach for subway tunnel deformation monitoring: high-resolution terrestrial laser scanning," ISPRS-International Archives of the Photogrammetry, vol. 5, no. 1, pp. 223-228, 2012.

[7] K. Chmelina, J. Jansa, G. Hesina, and G. Traxler, “A 3-d laser scanning system and scan data processing method for the monitoring of tunnel deformations," Journal of Applied Geodesy, vol. 6, no. 3, pp. 177-185, 2012.

[8] X. L. Zhang, M. C. He, F. N. Wang et al., "Study on the large deformation characteristics and disaster mechanism of a thinlayer soft-rock tunnel," Advances in Civil Engineering, vol. 2020, Article ID 8826337, 15 pages, 2020.

[9] S. Q. Yang, Y. Tao, P. Xu, and M. Chen, "Large-scale model experiment and numerical simulation on convergence deformation of tunnel excavating in composite strata," Journal of Mathematics, vol. 94, Article ID 103133, 2019.

[10] D. Hu, K. N. Zhang, and J. He, "Analysis of deformation of tunnel surrounding rock based on three dimensional finite element and improved grey theory," International Journal of Earth Sciences and Engineering, vol. 9, no. 4, pp. 1839-1844, 2016.
[11] G. Zheng, F. J. Wang, Y. M. Du, Y. Diao, Y. Lei, and X. Cheng, "The efficiency of the ability of isolation piles to control the deformation of tunnels adjacent to excavations," International Journal of Civil Engineering, vol. 16, no. 10, pp. 1475-1490, 2018.

[12] Q. Liu, G. Y. Lu, J. R. Huang, and D. Bin, "Development of tunnel intelligent monitoring and early warning system based on micro-service architecture: the case of AnPing tunnel," Geomatics Natural Hazards and Risk, vol. 11, no. 1, pp. 1404-1425, 2020.

[13] S. L. Tian, X. R. Ge, and Z. J. Tu, "Testing study on digital close-range photogrammetry for measuring deformations of tunnel and underground spaces," Chinese Journal of Rock Mechanics and Engineering, vol. 25, no. 7, p. 1309, 2006.

[14] G. R. Pan and W. Li, "Development and application of georobots in automatic monitoring of subway," Journal of Shandong University of Science and Technology, vol. 34, no. 2, 2015.

[15] S. T. Liu, D. Zhang, G. Wang, and B. Guo, "Automatic hydrostatic leveling system applied in rail transit line and tunnel monitoring," Urban Mass Transit, vol. 19, no. 10, 2016.

[16] X. Li and C. Y. Fang, "Bassett convergence system," Surveying and Mapping in Shanxi, vol. 11, no. 3/4, p. 34, 2004.

[17] S. T. Liu and H. F. Zhang, "Research progress of deformation monitoring technology for tunnel surrounding rock," Highway, vol. 9, p. 262, 2013.

[18] Y. Ding, B. Shi, and H. B. Sui, "Tunnel structural health monitoring system and fiber optic sensing technology," Journal of Disaster Prevention and Mitigation Engineering, vol. 25, no. 4, 2005.

[19] M. Wang, X. Li, Z. Y. Liu, and J. Liu, "Application of PIV technique in model test of frost heave of unsaturated soil," Journal of Cold Regions Engineering, vol. 34, no. 3, 2020.

[20] M. I. Peerun, D. E. L. Ong, and C. S. Choo, "Interpretation of geomaterial behavior during shearing aided by PIV technology," Journal of Materials in Civil Engineering, vol. 31, no. 9, 2019.

[21] H. L. Sun, Z. W. Xu, L. B. Yao, R. Zhong, L. Du, and H. Wu, "Tunnel monitoring and measuring system using mobile laser scanning: design and deployment," Remote Sensing, vol. 12, no. $4,2020$.

[22] D. S. Xu, "A new measurement approach for small deformations of soil specimens using fiber bragg grating sensors," Sensors, vol. 17, no. 5, 2017.

[23] D. S. Xu, J. Y. Tang, Y. Zhou, R. Rui, and H. B. Liu, "Macro and micro investigation of gravel content on simple shear behavior of sand-gravel mixture," Construction and Building Materials, vol. 221, pp. 730-744, 2019.

[24] D. S. Xu, M. Huang, and Y. Zhou, "One-dimensional compression behavior of calcareous sand and marine clay mixtures," International Journal of Geomechanics, vol. 20, no. 9, Article ID 04020137, 2020.

[25] D. S. Xu, X. Y. Xu, W. Li, and B. Fatahei, "Field experiments on laterally loaded piles for an offshore wind farm," Marine Structures, vol. 69, Article ID 102684, 2020.

[26] H. Z. Wei, D. S. Xu, and Q. S. Meng, "A newly designed fiberoptic based earth pressure transducer with adjustable measurement range," Sensors, vol. 18, no. 4, p. 932, 2018.

[27] D. S. Xu, F. B. Zhu, B. Lalit, X. Fan, and Q. Liu, "Construction solid waste landfills: risk assessment and monitoring by fibre optic sensing technique," Geomatics, Natural Hazards and Risk, vol. 12, no. 1, pp. 63-83, 2021.

[28] D. S. Xu, Z. W. Liu, B. Chen, and X. Y. Xu, "Bearing capacity analysis of offshore pipe piles with CPTs by considering 
uncertainly," Computers and Geotechnics, vol. 126, Article ID 103731, 2020.

[29] D. Peng, K. W. Xia, C. Y. Yu, and Q. Wang, "Monitoring and analysis of stratum deformation and subsidence overlying a shallow tunnel using distributed optical fiber sensing technology," Journal of Disaster Prevention and Mitigation Engineering, vol. 39, 2019.

[30] H. N. Wu, S. L. Shen, R. P. Chen, and A. N. Zhou, "Threedimensional numerical modelling on localised leakage in segmental lining of shield tunnels," Computers and Geotechnics, vol. 122, 2020.

[31] S. L. Shen, H. M. Lyu, A. N. Zhou, L. H. Lu, G. Li, and B. B. Lu, "Automatic control of groundwater balance to combat dewatering during construction of a metro system," Automation in Construction, vol. 123, 2021.

[32] Z. Niu, Z. G. Xu, G. Sun et al., "Design of a new multispectral waveform LiDAR instrument to monitor vegetation," IEEE Geoscience and Remote Sensing Letters, vol. 12, 2015.

[33] D. S. Xu, Q. C. Liu, Y. Qin, and B. Chen, “Analytical approach for crack identification of glass fiber reinforced polymer-sea sand concrete composite structures based on strain dissipations," Structural Health Monitoring, 2020.

[34] Z. X. Chen, R. Wang, M. J. Hu, Z. B. Wang, and D. S. Xu, "Study of content of clay particles for debris flow occurrence in Jiangjia Ravine," Rock and Soil Mechanics, vol. 31, no. 7, pp. 2197-2201, 2010. 